\title{
MEASURING THE IMPACT OF LEAN CONSTRUCTION PRACTICES ON PROJECT DURATION AND VARIABILITY: A SIMULATION-BASED STUDY ON RESIDENTIAL BUILDINGS
}

\author{
Huseyin EROL, Irem DIKMEN, M. Talat BIRGONUL \\ Department of Civil Engineering, Middle East Technical University, \\ Dumlupinar bulvarl-1, 06800 Ankara, Turkey
}

Received 03 Feb 2015; accepted 24 Mar 2015

\begin{abstract}
Performance of the construction projects have been criticized for many years due to their low productivity rates and cost overruns as well as significant delays. Increasing number of dissatisfied customers compel practitioners to reform conventional practices of construction management. Lean construction has emerged as a result of these efforts in the industry. However, there are limited number of studies that demonstrate the practical benefits of lean construction applications. The aim of this paper is to untangle practical applications of lean construction and to reveal their benefits. A methodology was developed to compare the lean and non-lean scenarios of a residential building project by means of Monte Carlo simulation. Simulation models were generated through regular meetings held with construction planning experts. Research findings demonstrate that application of lean construction principles have a potential to improve the performance of projects by reducing both the total project duration and its expected variation. In addition, the study revealed that utilization of practical lean construction principles may result in a considerable amount of time reduction in wall construction and plastering activities of residential building projects. Although the findings of this study cannot be generalized, they are expected to encourage practitioners to adopt lean construction principles.
\end{abstract}

Keywords: construction industry, construction management, lean construction, lean construction principles, scheduling, Monte Carlo simulation.

\section{Introduction}

Construction practitioners have developed numerous methods to assess the performance of a construction project. Schedule and budget performance are some quantitative metrics; while quality, occupational health and safety, and sustainability are qualitative ones. In the sense of satisfying these criteria, conventional practice of the construction management frequently fails (Koskela et al. 2002). Construction projects have unique attributes, such as on-site production, inimitability, and complexity. Apart from the combined effects of them; weather conditions, owner changes, and the interaction between multiple operations can produce high level of uncertainty (Salem et al. 2006). Under these circumstances, construction industry falls behind the other industries in terms of efficiency and customer satisfaction. For example, Aziz and Hafez (2013) stated that construction industry misspends 57 percent of the production time, whereas only 12 percent of time is waste in the manufacturing industry.

The poor performance of construction projects compels the industry to reconsider current construction management practices (Koskela 1992, 2000; Egan 1998;
Diekmann et al. 2004). As a result of the change efforts, lean principles emerged from the manufacturing industry have been adapted to construction projects. Lean construction is not only an endeavour to transform traditional practices, but also an innovation for construction companies to differentiate themselves. However, construction industry does not implement the lean principles as successful as the manufacturing industry, even though both industries have same goal of pleasing the customer by minimum time and resource consumption (Mao, Zhang 2008). Dynamics of the construction industry is incompatible with other industries due to the fact that it is a conservative sector. Traditional perception of doing business hinders the industry to adapt innovative solutions (Ozorhon et al. 2014). In addition to this, lean construction is still an ill-defined concept in terms of clarity and practicability (Alves et al. 2010). Although many tools and techniques are developed by researches to implement lean construction principles, they are regarded as invalid in practice.

To overcome these problems, this paper principally aims to untangle practical applications of lean construc-

Corresponding author: Huseyin Erol

E-mail:huseyinerol@yahoo.com 
tion philosophy and to reveal tangible benefits of lean construction to encourage practitioners to adopt its principles. In this respect, a simulation-based study has been carried out on residential buildings and results of a lean and non-lean scenario are compared through stochastic models. Results of the study demonstrate that practical applications of lean construction principles both reduce project duration and its expected variability. This study also compares lean construction principles in terms of their relative importance and provides insight about lean sensitivities of basic activity types in a small residential building project.

\section{Literature review}

\subsection{Lean construction}

Lean construction terminology exists in construction engineering and management domain since early 1990s. There are many fundamental principles that shaped philosophy of lean construction. Lean construction has emerged as consequence of tremendous impacts of lean production on manufacturing industry. Principles of lean production stem from Toyota Production System (TPS) (Holweg 2007). TPS predominantly aims to minimize all types of waste in the production process, while maximizing quality of the product, which is defined as value. Techniques developed within TPS to realize these purposes transferred to the West as lean production (Womack et al. 1990). Lean production has dramatically improved the performance of manufacturing industry. Consequently, Koskela (1992) offered a new production theory applicable to construction by combining lean production and other production theories. This theory constitutes the basis of lean construction. According to Mao and Zhang (2008) lean construction possesses three main characteristics that differentiate itself from traditional construction management techniques:

1. Lean construction aims to lessen any kind of wastes, such as inspection, transportation, waiting, and motion.

2. Lean construction intends to decrease variability and irregularity in order to ensure uninterrupted material and information flows.

3. Lean construction prefers to have construction material on site only when it is necessary.

\subsection{Application of lean construction principles}

In order to achieve previously mentioned objectives, many applications of lean construction principles have been developed. These applications, which are discussed in the following sections, are categorized under three main headings as: Lean Project Delivery System (LPDS), Last Planner System (LPS) of Production Control, and Practical Applications of Lean Construction Principles.

\section{(1) Lean Project Delivery System}

LPDS (Ballard 2000a) is integrated project delivery method of lean construction. Although it includes many elements from traditional practices, it harmonizes them with a holistic delivery system. LPDS is composed of five phases: project definition, lean design, lean supply, lean assembly, and facility use. The major contribution of LPDS is its integrated approach, which requires concurrent management of all phases. LPDS comprehensively analyses interaction of design and construction to minimize waste at each level (Alarcon, Mesa 2012). Moreover, facility use is accepted as a part of project delivery unlike to other project delivery systems (Koskela et al. 2002).

With these aspects, all phases of LPDS serves for fundamental principles of lean construction, such as reducing waste, generate value, and improving work flows. Ballard (2008) demonstrates the positive effects of LPDS on project performance with a real case evidence. A clinic project in which LPDS principles are implemented costs approximately 15 percent less than the project target cost. It is also completed 3.5 months ahead of the schedule.

\section{(2) Last Planner System of Production Control}

LPS (Ballard 1993, 2000b) is work structuring and control mechanism of lean construction. Current practices perform the planning prior to start of the project according to some suppositions. LPS, on the other hand, is based upon pulling work packages at defined time intervals to have a continuous work flow (Tommelein et al. 1998). In LPS applications, activities are generally drooped into a six week look-ahead window. For all activities within the plan period, potential constraints are defined, and no activity is allowed to start unless detailed work plans and solutions to potential constraints are promoted. Percentages of completed assignments are calculated for each plan period. At the end of the plan period, reasons for failure are described, and they are tried to be fixed in the following plan periods (Ballard et al. 2002). The pull approach of LPS shields activities from work flow uncertainty, and improves the productivity (Kim, Jang 2005).

According to Shang and Pheng (2014), LPS is the most powerful and well-known planning and control system among all the lean construction applications and tools. There are many examples showing benefits of LPS on project performance. Nieto-Morote and Ruz-Vila (2012) stated that six weeks implementation of the LPS to a chemical plant construction project significantly reduced the reasons for non-completion of planned activities. Another research shows that percent plan completion of the activities are considerably increased after implementation of LPS to two case study projects constructed in Saudi Arabia (AlSehaimi et al. 2014).

\section{(3) Practical Applications of Lean Construction Principles}

Implementing LPDS and LPS in practice requires long term commitment, as well as individual and organizational change. Despite the existence of the studies showing tangible benefits of them, contractors hesitate to utilize them in practice due to their theory-based and 
Table 1. Practical applications of lean construction principles

\begin{tabular}{|c|c|c|}
\hline ID & Lean construction principle & Reference study \\
\hline P1 & Increasing visualization through process transparency and computer aided visualization & Rischmoller et al. (2006) \\
\hline $\mathrm{P} 2$ & 3-D and 4-D design with building information modelling (BIM) and digital prototyping & Sacks et al. (2009) \\
\hline $\mathrm{P} 3$ & Utilization of time buffers & Alarcon and Ashley (1999) \\
\hline P4 & Minimizing material storage through Just-in-Time (JIT) delivery of materials & Hosseini et al. (2011) \\
\hline P5 & Utilization of multi-skilled labour & Sacks et al. (2007) \\
\hline P6 & Utilization of cross functional process charts & Tuholski et al. (2009) \\
\hline $\mathrm{P} 7$ & Utilization of construction process analysis & Lee et al. (1999) \\
\hline P8 & $\begin{array}{l}\text { Application of Five S(s) principles to construction (Sort, Straighten, Shine, Standardize, } \\
\text { Sustain) }\end{array}$ & Salem et al. (2006) \\
\hline P9 & Utilization of Poka-Yoke (Error-Proofing) methods & Bertelsen (2004) \\
\hline $\mathrm{P} 10$ & Utilization of value stream mapping & Aziz and Hafez (2013) \\
\hline P11 & Implementing pre-fabrication and pre-casting in construction process & Diekmann et al. (2004) \\
\hline $\mathrm{P} 12$ & Utilization of the data that collected from the previous projects & Tezel and Nielsen (2013) \\
\hline P13 & Utilization of risk management techniques & Issa (2013) \\
\hline P14 & Implementing safety and quality control plans & Misfeldt and Bonke (2004) \\
\hline $\mathrm{P} 15$ & $\begin{array}{l}\text { Optimizing the site conditions in terms of location of materials, construction access, and } \\
\text { movement of equipment }\end{array}$ & Diekmann et al. (2004) \\
\hline P16 & Levelling the production and crews & Sacks et al. (2010) \\
\hline $\mathrm{P} 17$ & Providing training at every level & Diekmann et al. (2004) \\
\hline $\mathrm{P} 18$ & Establishing long-term relationships with related parties of the project & Koskela (2000) \\
\hline P19 & Including all project participants to decision making process & Oskouie et al. (2012) \\
\hline $\mathrm{P} 20$ & Cooperating with different departments & Koskela (2000) \\
\hline $\mathrm{P} 21$ & Organizing regular meetings to improve the process & Salem et al. (2006) \\
\hline
\end{tabular}

abstruse approach. For this reason, many practical applications of lean construction principles have been evolved. They serve both as reinforcing principles to LPDS and LPS, and as individual principles that contribute to project performance in the short term. In this respect, Table 1 compiles the commonly-used practical applications along with literature examples that are either directly used or referred to related principles.

Practical applications of lean construction principles presented in Table 1 serve as a guideline for the practitioners who want to implement lean construction principles at the basic level. The most generic form of lean construction application is LPDS, including subset of LPS. Practical applications, on the other hand, are more specific implementation methods. Some of them are associated with LPDS and LPS, while other ones are independent principles. Moreover, some practical applications of lean construction principles are complementary for each other. For example, realizing minimum material storage (P4) in construction site is directly related to establishing long term relationships (P18) with suppliers. These links, as well as clusters of application of lean construction principles are shown in the Figure 1.

\subsection{Measuring the effects of lean construction applications}

Although practical applications of lean construction principles offered in this study have potential to encourage contractors to implement lean construction, there is still a necessity for identifying benefits of them by revealing

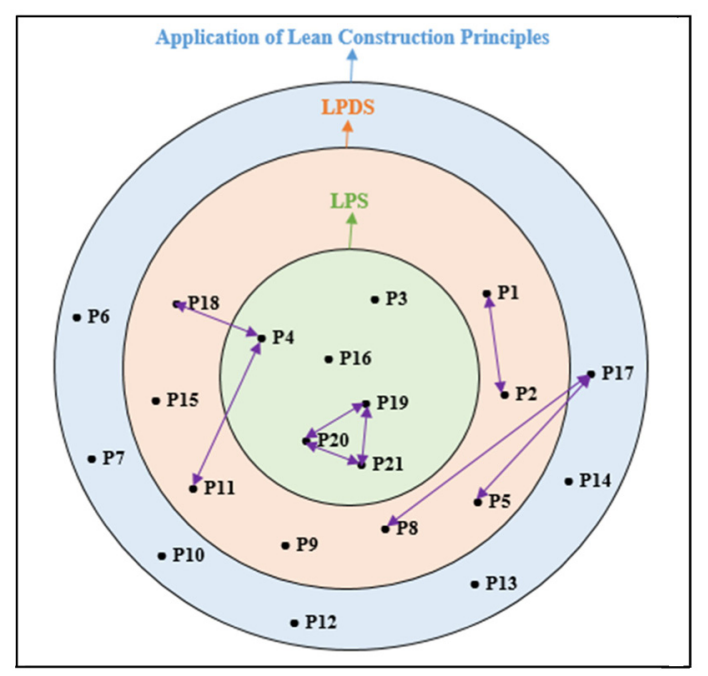

Fig. 1. Application map of lean construction principles 
quantitative results. Since physical simulation of lean construction is not possible due to prejudice of the practitioners, many simulation techniques have been promoted to measure the effects of lean construction principles. Computer enabled virtual simulation is a very effective and cheap way of testing proposed processes since computer technology allows fast computing despite great numbers of combinations. It serves as a validation tool before implementing lean principles on the site (Mao, Zhang 2008).

Discrete-event simulation is one of the most widely used techniques for simulating the lean principles (Hosseini et al. 2011; Sacks et al. 2007). Fundamentally, it models the operation of a system and explains the system behaviour according to sequence of event in time. However, complex structure of the discrete-event simulation prevents to exploit the advantages in a practical manner. Management games are also used for training purposes (Alarcon, Ashley 1999). Simulation games enable better understanding of lean construction principles. Nevertheless, as distinct from the discrete event simulation, these games are quite simple, and cannot be used as a validation tool for all cases. Another technique is Monte Carlo simulation, which simulates lean construction principles based on probabilistic techniques (Maturana et al. 2003). Even though it relies on subjective judgement, Monte Carlo simulation practically calculates optimistic, pessimistic, and most likely scenarios of a lean construction application.

Since this study aims to measure effects of the practical lean construction applications on project duration and variability, Monte Carlo simulation was utilized to compare lean and non-lean scenarios of a residential building project. The details of the research methodology are explained in the next section.

\section{Research methodology}

The research methodology is based on assessing the performance of a residential building project as simulationbased study under implementation of lean construction principles. For this purpose, two stochastic models were created to compare schedule performance of the project. One model employs practical applications of lean construction principles, whereas the other model does not incorporate them. In order to develop these models, regular meetings were held with three construction planning experts. Expert opinions were reflected to the models through a questionnaire responded at the last meeting. The research methodology is composed of five basic steps. The following is a brief description of these steps:

1. Identifying the practical lean construction principles that can be utilized in residential building projects.

2. Generating lean and non-lean scenarios to examine the impact of principles determined in the first step.

3. Choosing a residential building project as a simulation model.
4. Determining the activity durations of the simulation model for lean and non-lean scenarios according to responses of experts.

5. Carrying out Monte Carlo simulations in order to obtain quantitative appraisal of practical applications of lean construction principles.

(1) Step 1

First step includes specification of the lean construction principles used in this research. On the basis of the practical applications of lean construction principles demonstrated in Table 1, 14 principles were selected according to their applicability in residential building projects. These principles are: (1) providing training activities; (2) establishing long-term employee relationships; (3) using multi-skilled workforce; (4) improving the process transparency; (5) using the clean construction principles; (6) minimizing the material storage; (7) optimizing the site conditions; (8) establishing long-term supplier relationships; (9) encouraging the project participants for consensus-based decision making; (10) cooperating with different departments; (11) organizing regular meetings; (12) using time buffers; (13) using 4-D scheduling and simulation; and (14) using risk management techniques.

\section{(2) Step 2}

Second step develops the scenarios that help to measure the impacts of 14 lean construction principles introduced in the previous step. In this regard, two different scenarios were identified as lean and non-lean scenario. The difference of these scenarios stems from their approach to use practical applications of lean construction principles. Correspondingly, they are described as follows:

- Lean scenario employs all of the lean construction principles designated in the first step.

- Non-lean scenario does not carry out any of the 14 lean construction principles.

\section{(3) Step 3}

Third step introduces a simulation model that enables to experiment two scenarios generated in the preceding step. Various sources indicate that lean construction principles are quite appropriate to be used in repetitive projects (Yang, Ioannou 2001; Mao, Zhang 2008; Hosseini et al. 2011). Residential building projects have a repetitive nature. In other words, activities performed in a location do not show any differences in another location. For this reason, many researchers test their proposed lean construction methodologies through multi-storey buildings (Maturana et al. 2003; Sacks, Goldin 2007; Hosseini et al. 2011).

In this research, a residential building project was used as the simulation-based study due to aforementioned reasons. It is composed of two 8-storey and three 5-storey buildings as depicted by the 3-D model in Figure 2. The buildings are identical in terms of net floor area. Although the number of activities performed in 8 -storey buildings is more than those of 5-storey buildings, activity types and their durations are same for all buildings. 


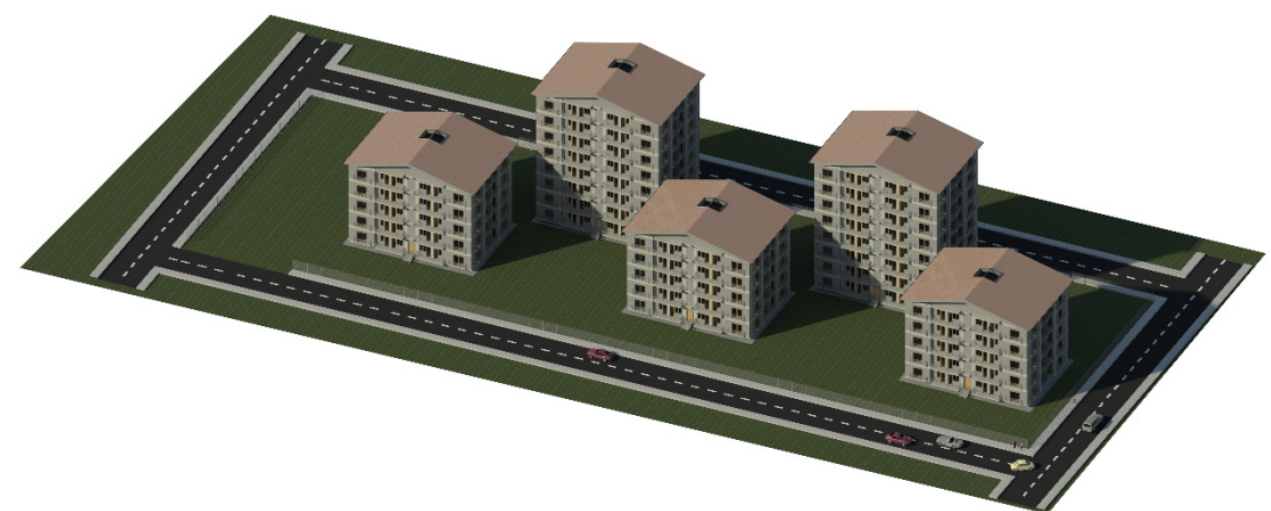

Fig. 2. 3-D view of the simulation-based project

\section{(4) Step 4}

Fourth step determines the activity durations of the simulation model for both lean and non-lean scenarios. Activity durations were appointed by collecting the necessary data from the experts. Monte Carlo simulation was utilized to compare schedule performance of the two scenarios.

Planning engineers generally prefers to use the most likely durations when they prepare the schedules. Nonetheless, the actual duration of an activity is generally different from the most likely duration due to predictable and unpredictable risks that construction works accompany with. For such circumstances; planners prefer to use probabilistic techniques, such as program evaluation and review technique (PERT) and Monte Carlo simulation to take into account both optimistic and pessimistic scenarios, as well as the most likely scenario. In this study, also a probabilistic approach was used to capture the effects of practical lean construction principles on both project duration and its variability. The reason why Monte Carlo simulation was chosen, instead of PERT, is explained by Barraza (2011) with following advantages of Monte Carlo simulation:

- Monte Carlo simulation provides more realistic estimations by taking into account the probability of each activity to become critical.

- As compared to Monte Carlo simulation, PERT gives extremely optimistic results.

Monte Carlo simulation represents the activity durations as probability distribution curves. Table 2 displays the activity types of the simulation model and their probability distribution curves. The project is composed of 535 activities in total. First two IDs of the table stand for start milestone and mobilization. IDs A1020 to A1080 show foundation works, and IDs A1090 to A1240 represent all activities in the first floor of the first 8-storey building. IDs A1250 to A6320 are repeated identically for remaining 7 stories of the first 8-storey building, second 8 -storey building, and three 5 -storey buildings. Finally, the last two IDs show demobilization and finish milestone.

The project includes 9 basic activity groups that experts evaluate their lean and non-lean scenarios. All of them have a triangular distribution. Therefore, experts es- timated optimistic (minimum), pessimistic (maximum), and most likely durations for both scenarios. Activities that do not have triangular distribution were reflected to two scenarios with same values. For instance; for the soil compaction activities, which have normal distribution, identical mean and standard deviation values are utilized in the simulation for lean and non-lean scenarios. The basic activity groups of the project are: excavation, reinforcement, formwork, concrete, backfill, walls, electrical installation, mechanical installation, and plastering. Experts were given the most likely durations of non-lean scenario for basic activity groups in terms of some coefficients. By using given coefficients; they estimated minimum and maximum durations of the non-lean scenario, as well as minimum, maximum, and most likely durations of the lean scenario as presented in Table 3.

Coefficients obtained from the experts for 9 basic activities were distributed to all related activities. Thereby; optimistic, pessimistic, and most likely durations of all activities were obtained for both scenarios. For example, coefficients of the formwork group were multiplied with the most likely durations of non-lean scenario for any formwork related activity. In other words, same coefficients were utilized for both formwork for foundation and formwork for column activities. The duration difference of these activities stems from the original most likely durations of non-lean scenario. Table 4 indicates the relationships of the 9 basic activities with other activities of the project.

To sum up, data collected from the experts was utilized to obtain minimum, most likely, and maximum durations of the activities for lean and non-lean scenarios. Coefficients obtained in this step; not only serve for carrying out Monte Carlo simulation for two scenarios, but also enable to compare basic activity types in terms of their sensitivity towards lean construction principles. Furthermore, in order to learn individual effects of the 14 lean construction principles on their estimations, experts were asked to classify them hierarchically in terms of their frequencies and impacts.

In order to construct this step, several face to face meetings were held with the construction planning experts. Specific lean construction approach of this research, 
Table 2. Activity types of the simulation model

\begin{tabular}{|c|c|c|}
\hline Activity ID & Activity name & Type of distribution curve \\
\hline A1000 & Start Milestone & - \\
\hline A1010 & Mobilization & Singular \\
\hline A 1020 & Excavation & Triangular \\
\hline A 1030 & Soil Compaction & Normal \\
\hline A1040 & Lean Concrete & Triangular \\
\hline A 1050 & Rebar for Foundation & Triangular \\
\hline A 1060 & Formwork for Foundation & Triangular \\
\hline A1070 & Concrete for Foundation & Triangular \\
\hline A1080 & Backfill for Foundation & Triangular \\
\hline A1090 & Floor 1-Section X Column Rebar & Triangular \\
\hline A1100 & Floor 1-Section X Column Formwork & Triangular \\
\hline A1110 & Floor 1-Section X Column Concrete & Triangular \\
\hline A1120 & Floor 1-Section X Beam-Slab Rebar & Triangular \\
\hline A1130 & Floor 1-Section X Beam-Slab Formwork & Triangular \\
\hline A1140 & Floor 1-Section X Beam-Slab Concrete & Triangular \\
\hline A1150 & Floor 1-Section Y Column Rebar & Triangular \\
\hline A1160 & Floor 1-Section Y Column Formwork & Triangular \\
\hline A1170 & Floor 1-Section Y Column Concrete & Triangular \\
\hline A1180 & Floor 1-Section Y Beam-Slab Rebar & Triangular \\
\hline A1190 & Floor 1-Section Y Beam-Slab Formwork & Triangular \\
\hline A1200 & Floor 1-Section Y Beam-Slab Concrete & Triangular \\
\hline A 1210 & Floor 1-Walls & Triangular \\
\hline A 1220 & Floor 1-Electrical Installation & Triangular \\
\hline A1230 & Floor 1-Mechanical Installation & Triangular \\
\hline A1240 & Floor 1-Plastering & Triangular \\
\hline A1250-A6320 & (Repeated Identically) & $\ldots$ \\
\hline A6330 & Demobilization & Trapezoidal \\
\hline A6340 & Finish Milestone & - \\
\hline
\end{tabular}

Table 3. Identification of the activity durations for both scenarios

\begin{tabular}{l|c|c|c|c|c|c}
\hline \multicolumn{1}{c|}{ Activity group } & $\mathrm{t}_{\text {nonlean }}$ & $\mathrm{t}_{\text {nonlean-min }}$ & $\mathrm{t}_{\text {nonlean-max }}$ & $\mathrm{t}_{\text {lean-min }}$ & $\mathrm{t}_{\text {lean }}$ & $\mathrm{t}_{\text {lean-max }}$ \\
\hline Excavation & $\mathrm{t}_{1}$ & $\begin{array}{c}\text { function of } \mathrm{t}_{1} \\
\left(\mathrm{E} . \mathrm{g} .: 0.95 \mathrm{t}_{1}\right)\end{array}$ & $\begin{array}{c}\text { function of } \mathrm{t}_{1} \\
\left(\mathrm{E} . \mathrm{g} .: 1.30 \mathrm{t}_{1}\right)\end{array}$ & $\begin{array}{c}\text { function of } \mathrm{t}_{1} \\
\left(\mathrm{E} \text {.g.: } 0.9 \mathrm{t}_{1}\right)\end{array}$ & $\begin{array}{c}\text { function of } \mathrm{t}_{1} \\
\left(\mathrm{E} \text {.g.: } 0.95 \mathrm{t}_{1}\right)\end{array}$ & $\begin{array}{c}\text { function of } \mathrm{t}_{1} \\
\left(\mathrm{E} \text {.g.: } 1.15 \mathrm{t}_{1}\right)\end{array}$ \\
\hline Reinforcement & $\mathrm{t}_{2}$ & function of $\mathrm{t}_{2}$ & function of $\mathrm{t}_{2}$ & function of $\mathrm{t}_{2}$ & function of $\mathrm{t}_{2}$ & ${\text { function of } \mathrm{t}_{2}}$ \\
\hline Formwork & $\mathrm{t}_{3}$ & function of $\mathrm{t}_{3}$ & function of $\mathrm{t}_{3}$ & function of $\mathrm{t}_{3}$ & function of $\mathrm{t}_{3}$ & function of $\mathrm{t}_{3}$ \\
\hline Concrete & $\mathrm{t}_{4}$ & function of $\mathrm{t}_{4}$ & function of $\mathrm{t}_{4}$ & function of $\mathrm{t}_{4}$ & function of $\mathrm{t}_{4}$ & function of $\mathrm{t}_{4}$ \\
\hline Backfill & $\mathrm{t}_{5}$ & function of $\mathrm{t}_{5}$ & function of $\mathrm{t}_{5}$ & function of $\mathrm{t}_{5}$ & function of $\mathrm{t}_{5}$ & function of $\mathrm{t}_{5}$ \\
\hline Walls & $\mathrm{t}_{6}$ & function of $\mathrm{t}_{6}$ & function of $\mathrm{t}_{6}$ & function of $\mathrm{t}_{6}$ & function of $\mathrm{t}_{6}$ & function of $\mathrm{t}_{6}$ \\
\hline Electrical Installation & $\mathrm{t}_{7}$ & function of $\mathrm{t}_{7}$ & function of $\mathrm{t}_{7}$ & function of $\mathrm{t}_{7}$ & function of $\mathrm{t}_{7}$ & function of $\mathrm{t}_{7}$ \\
\hline Mechanical Installation & $\mathrm{t}_{8}$ & function of $\mathrm{t}_{8}$ & function of $\mathrm{t}_{8}$ & function of $\mathrm{t}_{8}$ & function of $\mathrm{t}_{8}$ & function of $\mathrm{t}_{8}$ \\
\hline Plastering & $\mathrm{t}_{9}$ & function of $\mathrm{t}_{9}$ & function of $\mathrm{t}_{9}$ & function of $\mathrm{t}_{9}$ & function of $\mathrm{t}_{9}$ & function of $\mathrm{t}_{9}$ \\
\hline
\end{tabular}

practical applications used in the models, details of the scenarios, Monte Carlo simulation model, and residential building project of the study were comprehensively discussed during these meetings. They estimated the coefficients, and classified 14 lean construction principles by means of a questionnaire distributed at the last meeting.

Three experts who contributed to this study have substantial experience in construction planning and lean construction. Expert A is the general manager of a con- sultancy firm. The company that he manages provides consultancy services in all areas of project management for the construction and engineering works. In this respect, Expert A inspects different construction sites all around the world more than ten years. By virtue of his field observations, he knows the current construction management practices and their weaknesses very well. For this reason, he is accustomed to lean construction principles, which aims to remove these weaknesses. Ex- 
Table 4. Classification of the activities

\begin{tabular}{l|l}
\hline \multicolumn{1}{c|}{ Basic activity group } & \multicolumn{1}{c}{ Related activity of the simulation model } \\
\hline Excavation & Excavation \\
\hline Reinforcement & $\begin{array}{l}\text { Rebar for Foundation, Section X Column Rebar, Section X Beam-Slab Rebar, Section Y } \\
\text { Column Rebar, Section Y Beam-Slab Rebar }\end{array}$ \\
\hline Formwork & $\begin{array}{l}\text { Formwork for Foundation, Section X Column Formwork, Section X Beam-Slab Formwork, } \\
\text { 1Section Y Column Formwork, Section Y Beam-Slab Formwork }\end{array}$ \\
\hline Concrete & $\begin{array}{l}\text { Lean Concrete, Concrete for Foundation, Section X Column Concrete, Section X Beam-Slab } \\
\text { Concrete, Section Y Column Concrete, Section Y Beam-Slab Concrete }\end{array}$ \\
\hline Backfill & Backfill for Foundation \\
\hline Walls & Walls \\
\hline Electrical Installation & Electrical Installation \\
\hline Mechanical Installation & Mechanical Installation \\
\hline Plastering & Plastering \\
\hline
\end{tabular}

pert $\mathrm{B}$, on the other hand, is a $\mathrm{PhD}$ candidate civil engineer who is working in a construction firm that conducts medium-sized building projects, in several of which the client is the government. He contributed to research from the viewpoint of a planning engineer who has more than five years of experience in residential building projects. In addition to his knowledge of scheduling, he has broad information regarding the lean construction concept by means of his studies in the academia. Finally, Expert $\mathrm{C}$ is an associate professor in a respected university of Turkey. He has specialized in construction planning and project management for many years. As an academician, he also has extensive knowledge regarding the lean construction philosophy. Besides, his experiences as a field engineer early in his career make him very much aware of practices on the site. Three participants of this study have unique expertise on different fields of the construction industry. Their diversification gives opportunity to examine the effects of practical applications of lean construction principles from the viewpoints of different professionals.

(5) Step 5

Last step of the research methodology is related to carrying out Monte Carlo simulation by using the data generated in the previous step. For this purpose, @Risk (1997) software was utilized to carry out Monte Carlo simulation. It allows the user to use practical functions of the spreadsheet, and to perform simulations quite easily. Moreover, it enables the users to conduct flexible analyses on the simulation graphs.

Prior to Monte Carlo simulations, activities of the simulation model have been scheduled in the spreadsheet according to following assumptions:

- Land purchasing and design activities are completed.

- Finishing works are not included in the project.

- Conventional formwork systems are used for concrete operations, which require separate concreting for columns and beam-slabs.

- Rebar, formwork, and concrete activities of the floors are performed in two successive sections, which are Section $\mathrm{X}$ and Section $\mathrm{Y}$.
- Holidays are not introduced to the project.

- Working days equal to 8 hours.

The high numbers of activities and complex activity relationship have challenged the accuracy of the spreadsheet model. For this reason, the schedule was reorganized by utilizing planning software. The accuracy of the spreadsheet model was ensured by obtaining same schedule results with the planning software. After the validation, the simulation was performed for lean and non-lean scenarios separately by iterating activity durations 10,000 times via@Risk.

\section{Research findings}

\subsection{Relative importance of the lean principles}

Since individual effects of the lean construction principles cannot be identified in the simulation models, experts were asked to compare 14 principles in terms of their relative importance. Experts estimated frequency of implementing lean principle in construction sites, and their positive impacts on the project performance when they are utilized. They used 1 to 5 rating scale, and relative importance was calculated by multiplying frequencies and impacts. Table 5 displays the average results provided by the experts.

According to results, the most significant lean construction principle is cooperating with different departments, which is followed by organizing regular meetings, and establishing long-term supplier relationships. All of these principles highlight the importance of the communication in construction works. Responses indicate that lack of communication may be a predominant factor in poor performance of the construction industry. In this respect, holistic and communication-based approach of lean construction has a great potential to lift the industry. On the other hand, some lean construction principles seem not convenient yet to be implemented in practice. Using multi-skilled workforce is primary of them. During the meetings, all experts have stated that this principle is very hard to be implemented in practice. Similarly, improving the involvement of work force 
Table 5. Relative importance of the lean construction principles

\begin{tabular}{l|l|c|c|c}
\hline ID & \multicolumn{1}{|c|}{ Lean construction principles } & Frequency & Impact & Relative importance \\
\hline P1 & Providing training activities & 3.00 & 3.67 & 11.00 \\
\hline P2 & Establishing long-term employee relationships & 3.00 & 3.67 & 11.00 \\
\hline P3 & Using multi-skilled workforce & 2.33 & 2.33 & 5.44 \\
\hline P4 & Improving the process transparency & 2.33 & 3.00 & 7.00 \\
\hline P5 & Using the clean construction principles & 3.00 & 3.00 & 9.00 \\
\hline P6 & Minimizing the material storage & 3.00 & 3.00 & 9.00 \\
\hline P7 & Optimizing the site conditions & 3.33 & 3.67 & 12.22 \\
\hline P8 & Establishing long-term supplier relationships & 3.67 & 4.33 & 15.89 \\
\hline P9 & Encouraging the project participants for & 3.33 & 4.33 & 14.44 \\
\hline P10 & Cooperating with different departments & 4.00 & 4.33 & 17.33 \\
\hline P11 & Organizing regular meetings & 4.00 & 4.00 & 16.00 \\
\hline P12 & Using time buffers & 2.67 & 3.00 & 8.00 \\
\hline P13 & Using 4-D scheduling and simulation & 2.00 & 4.00 & 8.00 \\
\hline P14 & Using risk management techniques & 2.67 & 3.67 & 9.78 \\
\hline
\end{tabular}

through process transparency is not believed to improve project performance, especially in Turkey. According to Expert A and C, low importance score of 4-D scheduling and simulation stems from its incompatibility with small-sized residential building projects. Finally, using time buffers directly extends the project duration, so it is determined as one of the least significant principles. To summarize, lean construction principles seems quite appropriate to remove communication barriers within the industry. However, some principles have not been validated by the construction practitioners yet, and they require further investigation.

\subsection{Lean sensitivities of the activities}

Combined effects of practical applications on 9 basic activity groups can be traced via averages of the coefficients assigned by the experts. The mean values of these coefficients were calculated according to a triangular distribution as presented in Table 6. Results show that for all activity types, mean values of the triangular distribu- tions are reduced in lean scenario as compared to nonlean scenario.

Among basic activity groups, wall activities has the highest time reduction percentage in lean scenario. When individual responses are investigated, coefficients of Expert $\mathrm{A}$ and Expert $\mathrm{C}$ reduce most in wall activities, while the most significant reduction in coefficients belongs to plastering activities, which is also a wall related activity, according to Expert B. During regular meetings, Expert A has indicated that practical applications offered in this study have a great potential to improve productivity of the labour force. Both wall construction and plastering activities considerably depend on the performance of workers. Therefore, wall and plastering activities have been considered as the most lean sensitive activity types by the experts. Results derived from this section emphasize that lean construction principles have positive influences on all activity types in terms of reducing their durations, and performance of the wall construction and plastering activities are significantly improved when they are utilized.

Table 6. Mean of the activity coefficients for both scenarios

\begin{tabular}{l|c|c|c}
\hline \multirow{2}{*}{\multicolumn{1}{c|}{ Activity group }} & \multicolumn{2}{c|}{ Mean of the coefficients $\left[\mathrm{t}_{\text {min }}{ }^{\left.-t_{\text {mostlikely }}{ }^{-t_{\text {max }}}\right]}\right.$} & \multirow{2}{*}{ Percent reduction } \\
\cline { 2 - 4 } & Non-lean scenario & Lean scenario & $8.40 \%$ \\
\hline Excavation & $1.055[0.833-1.000-1.333]$ & $0.967[0.800-0.933-1.167]$ & $8.02 \%$ \\
\hline Reinforcement & $1.072[0.883-1.000-1.333]$ & $0.986[0.850-0.925-1.183]$ & $5.22 \%$ \\
\hline Formwork & $1.061[0.850-1.000-1.333]$ & $1.006[0.842-0.958-1.217]$ & $5.30 \%$ \\
\hline Concrete & $1.056[0.917-1.000-1.250]$ & $1.000[0.883-0.958-1.158]$ & $7.47 \%$ \\
\hline Wackfill & $1.045[0.867-1.000-1.267]$ & $0.967[0.833-0.917-1.150]$ & $13.24 \%$ \\
\hline Electrical Installation & $1.133[0.900-1.000-1.500]$ & $0.983[0.850-0.917-1.183]$ & $10.38 \%$ \\
\hline Mechanical Installation & $1.072[0.850-1.000-1.367]$ & $0.961[0.833-0.917-1.133]$ & $9.08 \%$ \\
\hline Plastering & $1.072[0.867-1.000-1.350]$ & $0.975[0.850-0.942-1.113]$ & $10.25 \%$ \\
\hline
\end{tabular}


Total Project Duration-Lean Scenario

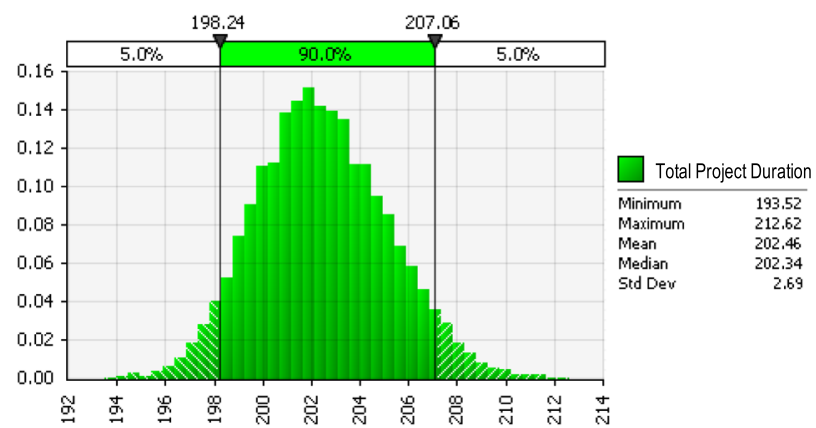

Fig. 3. Monte Carlo simulation of lean scenario

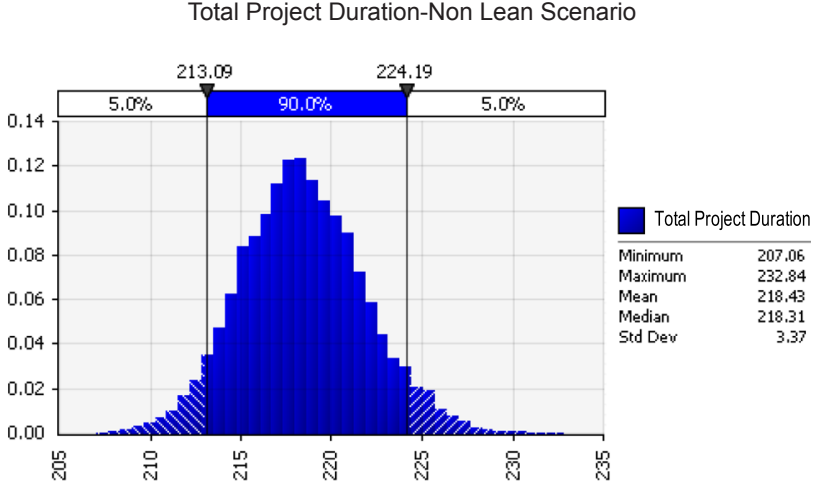

Fig. 4. Monte Carlo simulation of non-lean scenario

Table 7. Duration indicators of the simulation model

\begin{tabular}{c|l|c|c|c|c}
\hline Duration type & \multicolumn{1}{|c|}{ Duration performance } & Expert A & Expert B & Expert C & Average \\
\hline \multirow{4}{*}{ Optimistic } & Non-Lean Duration & 208.37 & 210.24 & 205.10 & 207.06 \\
\cline { 2 - 6 } & Lean Duration & 195.16 & 196.38 & 192.49 & 193.52 \\
\cline { 2 - 6 } & Time-Saving & 13.21 & 13.86 & 12.61 & 13.54 \\
\cline { 2 - 6 } & Percent Reduction & $6.34 \%$ & $6.59 \%$ & $6.15 \%$ & $6.54 \%$ \\
\hline \multirow{5}{*}{ Pessimistic } & Non-Lean Duration & 238.89 & 230.92 & 230.80 & 232.84 \\
\cline { 2 - 6 } & Lean Duration & 216.05 & 213.26 & 212.11 & 212.62 \\
\cline { 2 - 6 } & Time-Saving & 22.84 & 17.66 & 18.69 & 20.22 \\
\cline { 2 - 6 } & Percent Reduction & $9.56 \%$ & $7.65 \%$ & $8.10 \%$ & $8.68 \%$ \\
\hline \multirow{5}{*}{ Most Likely } & Non-Lean Duration & 221.76 & 219.14 & 215.86 & 218.43 \\
\cline { 2 - 6 } & Lean Duration & 203.78 & 204.28 & 201.55 & 202.46 \\
\cline { 2 - 6 } & Time Saving & 17.98 & 14.86 & 14.31 & 15.97 \\
\cline { 2 - 6 } & Percent Reduction & $8.11 \%$ & $6.78 \%$ & $6.63 \%$ & $7.31 \%$ \\
\hline
\end{tabular}

Table 8. Variability indicators of the simulation model

\begin{tabular}{l|c|c|c|c}
\hline \multicolumn{1}{c|}{ Variability performance } & Expert A & Expert B & Expert C & Average \\
\hline Non-Lean Standard Deviation & 4.11 & 2.86 & 3.75 & 3.37 \\
\hline Lean Standard Deviation & 2.76 & 2.45 & 2.81 & 2.69 \\
\hline Percent Reduction & $32.85 \%$ & $14.34 \%$ & $25.07 \%$ & $20.18 \%$ \\
\hline
\end{tabular}

\subsection{Total project duration}

Monte Carlo simulation results reveal the effects of the lean construction principles on project duration. Figures 3 and 4 show the probability distribution curves of the total project duration with 90 percent confidence intervals for lean and non-lean scenario, respectively.

Probability distribution curves were generated by simulating average durations estimated by the all experts. Individual results provided by the experts are also represented in Table 7. Simulation results include optimistic, pessimistic, and most likely durations. The reason why duration values are not integer is that @ Risk calculates simulation with non-integer numbers. According to simulation results, all durations were decreased in lean scenario. When average rounded up durations of all experts are considered with mean values, total project duration decreased 16 days by using lean construction principles.
In terms of percentages, there is a 7.31 percent reduction in the total project duration. Duration performance of the simulation model demonstrates that lean construction principles achieve a considerable amount of time reduction in small-sized residential building projects.

\subsection{Variability of the project duration}

In addition to total project duration, simulation results also explain the effects of the lean construction principles on variability of the project duration. Accordingly, standard deviation values for total project duration are organized in Table 8 for lean and non-lean scenarios of all experts. Besides, reduction percentages of standard deviation in lean scenario are included. Results indicate that, when average of all experts is considered, standard deviation of the total project is decreased 20.18 percent. Therefore, research findings promote that lean construc- 
tion principles decrease variability of the project duration in small-sized residential building projects, and allow more levelled production.

\section{Conclusions}

In this paper, a methodology was developed to demonstrate the benefits of lean principles and to encourage contractors for implementation of lean construction principles. For this purpose; stochastic models, which serve for comparing the schedule performance of a residential building project for lean and non-lean scenarios, were developed. The major outcomes of the study demonstrated that practical applications of lean construction principles both enhance project delivery time and reduce work flow variability. When probabilistic results conveyed by all participants are considered; including the most optimistic and the most pessimistic estimations, the lean construction principles led to 6.15 percent to 9.56 percent reduction in total project duration. Similarly, they decreased the standard deviation of the total project duration in the range of 14.34 percent to 32.85 percent. In addition, the study revealed that utilization of practical lean construction principles result in considerable amount of time reduction in all activity types of a residential building project, especially in wall construction and plastering activities. The potential of practical applications in terms of being a remedy to communication problems within the industry was also uncovered within this research.

This study is based on representing tangible benefits of the lean construction principles by subjective estimations of the experts, so performance improvements observed in the study are only valid for small-size residential projects undertaken in Turkey. The research can be enriched further by including representatives of owners, suppliers, contractors, and workforce to the expert profile in order to measure lean construction effects from the point of views of all construction project participants. Moreover, the methodology employed in this study may be improved further by adding new principles that are applicable to different types of construction works apart from residential building projects. Finally, an action research type of study may measure the performances of another metrics such as, cost, quality, health and safety, and sustainability in real projects. By this way, practitioners are expected to utilize lean construction principles in practice more frequently and realize full potential of the lean construction philosophy.

\section{Disclosure statement}

Authors of this article do not have any competing financial, professional, or personal interests from other parties.

\section{References}

Alarcon, L. F.; Ashley, D. B. 1999. Playing games: evaluating the impact of lean production strategies on project cost and schedule, in Proceedings of the $7^{\text {th }}$ Annual Conference of the International Group for Lean Construction, 26-28 July 1999, Berkeley, USA, 263-274.

Alarcon, L. F.; Mesa, H. 2012. A modelling approach to understand performance of lean project delivery system, in Proceedings of the $20^{\text {th }}$ Annual Conference of the International Group for Lean Construction, 18-20 July 2012, San Diego, USA. 10 p.

AlSehaimi, A.; Fazenda, P. T.; Koskela, L. 2014. Improving construction management practice with the last planner system: a case study, Engineering, Construction and Architectural Management 21: 51-64. http://dx.doi.org/10.1108/ECAM-03-2012-0032

Alves, T. C. L.; Milberg, C.; Walsh, K. D. 2010. Exploring lean construction practice, research, and education, in Proceedings of the $18^{\text {th }}$ Annual Conference of the International Group for Lean Construction, 14-16 July 2010, Haifa, Israel, 435-444.

Aziz, R. F.; Hafez, S. M. 2013. Applying lean thinking in construction and performance improvement, Alexandria Engineering Journal 52(4): 679-695. http://dx.doi.org/10.1016/j.aej.2013.04.008

Ballard, G. 1993. Lean construction and EPC performance improvement, in Proceedings of the $1^{\text {st }}$ Annual Conference of the International Group for Lean Construction, 1993, Espoo, Finland. 11 p.

Ballard, G. 2000a. Lean project delivery system. Lean Construction Institute (LCI), White Paper - No. 8, Las Vegas, Nevada, USA.

Ballard, G. 2000b. The last planner system of production control: $\mathrm{PhD}$ thesis. The University of Birmingham, Birmingham, UK.

Ballard, G. 2008. Lean project delivery system: an update, Lean Construction Journal, 1-19.

Ballard, G.; Tommelein, I.; Koskela, L.; Howell, G. 2002. Lean construction tools and techniques, Chapter 15 in R. Best, G. de Valence (Eds.). Design and construction: Building in value. Oxford, UK: Butterworth-Heinemann, 227-255.

Barraza, G. A. 2011. Probabilistic estimation and allocation of project time contingency, Journal of Construction Engineering and Management 137(4): 259-265. http://dx.doi.org/10.1061/(ASCE)CO.1943-7862.0000280

Bertelsen, S. 2004. Lean construction: where are we and how to proceed?, Lean Construction Journal 1(1): 46-69.

Diekmann, J. E.; Krewedl, M.; Balonick, J.; Stewart, T.; Won, S. 2004. Application of lean manufacturing principles to construction. A report to the construction industry institute. The University of Texas, Austin, Texas, USA. 325 p.

Egan, J. 1998. Rethinking construction. The report of the construction task force. DETR, London. 37 p.

Holweg, M. 2007. The genealogy of lean production, Journal of Operations Management 25(2): 420-437. http://dx.doi.org/10.1016/j.jom.2006.04.001

Hosseini, S. A. A.; Nikakhtar, A.; Wong, K. Y.; Zavichi, A. 2011. Implementing lean construction theory to construction processes' waste management, in Proceedings of the International Conference on Sustainable Design and Construction, 2011, Kansas City, USA, 414-420. http://dx.doi.org/10.1061/41204(426)52

Issa, U. A. 2013. Implementation of lean construction techniques for minimizing the risk effect on project construction time, Alexandria Engineering Journal 52(4): 697704. http://dx.doi.org/10.1016/j.aej.2013.07.003

Kim, Y. W.; Jang, J. W. 2005. Case study: An application of last planner to heavy civil construction in Korea, in Proceedings of the $13^{\text {th }}$ Annual Conference of the International Group for Lean Construction, 19-21 July 2005, Sydney, Australia, 405-411. 
Koskela, L. 1992. Application of the new production philosophy to construction. CIFE Technical Report. Stanford University, Stanford. $75 \mathrm{p}$.

Koskela, L. 2000. An exploration towards a production theory and its application to construction. VTT Technical Research Centre of Finland, Espoo, Finland. 298 p.

Koskela, L.; Howell, G.; Ballard, G.; Tommelein, I. 2002. The foundations of lean construction, Chapter 14 in R. Best, G. de Valence (Eds.). Design and construction: building in value. Oxford, UK: Butterworth-Heinemann, 211-226.

Lee, S. H.; Diekmann, J. E.; Songer, A. D.; Brown, H. 1999. Identifying waste: application of construction process analysis, in Proceedings of the $7^{\text {th }}$ Annual Conference of the International Group for Lean Construction, 26-28 July 1999, Berkeley, USA, 63-72.

Mao, X.; Zhang, X. 2008. Construction process reengineering by integrating lean principles and computer simulation techniques, Journal of Construction Engineering and Management 134(5): 371-381.

http://dx.doi.org/10.1061/(ASCE)0733-9364(2008)134:5(371)

Maturana, S.; Alarcon, L. F.; Deprez, M. 2003. Modeling the impact of multiskilling and concrete batch size in multistory buildings, in Proceedings of the $11^{\text {th }}$ Annual Conference of the International Group for Lean Construction, 2003, Virginia, USA. 9 p.

Misfeldt, E.; Bonke, S. 2004. Quality control in lean construction, in Proceedings of the $12^{\text {th }}$ Annual Conference of the International Group for Lean Construction, 2004, Copenhagen, Denmark. 12 p.

Nieto-Morote, A.; Ruz-Vila, F. 2012. Last planner control system applied to a chemical plant construction, Journal of Construction Engineering and Management 138(2): 287-293. http://dx.doi.org/10.1061/(ASCE)CO.1943-7862.0000415

Oskouie, P.; Gerber, D. J.; Alves, T.; Becerik-Gerber, B. 2012. Extending the interaction of building information modelling and lean construction, in Proceedings of the $20^{\text {th }}$ Annual Conference of the International Group for Lean Construction, 18-20 July 2012, San Diego, USA. 10 p.

Ozorhon, B.; Abbott, C.; Aouad, G. 2014. Integration and leadership as enablers of innovation in construction: case study, Journal of Management in Engineering 30(2): 256-263. http://dx.doi.org/10.1061/(ASCE)ME.1943-5479.0000204

Rischmoller, L.; Alarcon, L. F.; Koskela, L. 2006. Improving value generation in the design process of industrial projects using CAVT, Journal of Management in Engineering 22(2): 52-60. http://dx.doi.org/10.1061/(ASCE)0742-597X(2006)22:2(52)

@ Risk. 1997. Advanced risk analysis for spreadsheets: user manual. Palisade Corp., Newfield, New York.
Sacks, R.; Goldin, M. 2007. Lean management model for construction of high-rise apartment buildings, Journal of Construction Engineering and Management 133(5): 374-384. http://dx.doi.org/10.1061/(ASCE)0733-9364(2007)133:5(374)

Sacks, R.; Esquenazi, A.; Goldin, M. 2007. LEAPCON: Simulation of lean construction of high-rise apartment buildings, Journal of Construction Engineering and Management 133(7): 529-539.

http://dx.doi.org/10.1061/(ASCE)0733-9364(2007)133:7(529)

Sacks, R.; Treckman, M.; Rozenfeld, O. 2009. Visualization of work flow to support lean construction, Journal of Construction Engineering and Management 135(12): 1307-1315. http://dx.doi.org/10.1061/(ASCE)CO.1943-7862.0000102

Sacks, R.; Koskela, L.; Dave, B. A.; Owen, R. 2010. Interaction of lean and building information modelling in construction, Journal of Construction Engineering and Management 136(9): 968-980. http://dx.doi.org/10.1061/(ASCE)CO.1943-7862.0000203

Salem, O.; Solomon, J.; Genaidy, A.; Minkarah, I. 2006. Lean construction: from theory to implementation, Journal of Management in Engineering 22(4): 168-175.

http://dx.doi.org/10.1061/(ASCE)0742-597X(2006)22:4(168)

Shang, G.; Pheng, L. S. 2014. The last planner system in China's construction industry-a SWOT analysis on implementation, International Journal of Project Management 32(7): 1260-1272. http://dx.doi.org/10.1016/j.ijproman.2014.01.002

Tezel, A.; Nielsen, Y. 2013. Lean construction conformance among construction contractors in Turkey, Journal of Management in Engineering 29(3): 236-250. http://dx.doi.org/10.1061/(ASCE)ME.1943-5479.0000145

Tommelein, I.; Riley, D.; Howell, G. A. 1998. Parade game: impact of work flow variability on succeeding trade performance, in Proceedings of the $6^{\text {th }}$ Annual Conference of the International Group for Lean Construction, 1998, Guaruja, Brazil, 304-310.

Tuholski, S. J.; Gursel, A. P; Tommelein, I.; Bomba, G. 2009. "Lean" comparison using process charts of complex seismic retrofit projects, Journal of Construction Engineering and Management 135(4): 330-339.

http://dx.doi.org/10.1061/(ASCE)0733-9364(2009)135:4(330)

Womack, J. P.; Jones, D. T.; Roos, D. 1990. The machine that changed the world. New York: Rawson Associates. $352 \mathrm{p}$.

Yang, T.; Ioannou, P. G. 2001. Resource driven scheduling for repetitive projects: a pull-system approach, in Proceedings of the $9^{\text {th }}$ Annual Conference of the International Group for Lean Construction, 2001, Singapore, Singapore. 14 p.

Hüseyin EROL. PhD student and research assistant in the Construction Management and Engineering Division of the Civil Engineering Department in the Middle East Technical University. His primary research interests include lean construction, stochastic planning, 4D scheduling and simulation, BIM and construction process management.

Irem DIKMEN. Professor and lecturer in the Construction Management and Engineering Division of the Civil Engineering Department in the Middle East Technical University. Her primary research interests include risk management, knowledge management, strategic management of construction companies and use of IT to improve the construction value chain. She also conducts extensive research in the area of risk management of BOT projects in Turkey. In addition to her research activities, she gives continuing education seminars and consultancy services to construction professionals about international business development and construction risk management.

M. Talat BIRGONUL. Professor and lecturer in the Construction Management and Engineering Division of the Civil Engineering Department in the Middle East Technical University. His primary research interests include engineering economy, international construction, construction planning, macroeconomic aspects of the construction industry and claim management. Apart from his academic activities, he acts as an expert witness in Turkish courts and Arbitral Tribunals and gives a claim management consultancy service to leading construction companies. Currently, he is acting as the director of Construction Management and Engineering Division of the Civil Engineering Department in the Middle East Technical University. 